\title{
SKIN LESIONS IN DERMATOLOGIC OUTPATIENT CHILDREN WITH COVID-19 SUSPICION
}

\author{
Antônio Urbano Monteiro Neto ${ }^{1}$, David Duarte Timponi França ${ }^{1}$, Aline Mendonça Galvão \\ de Carvalho Aguiar ${ }^{1}$, Rebecca Castelo Branco de Brito ${ }^{1}$, and Vanessa Lucilia Silveira de \\ Medeiros $^{1}$ \\ ${ }^{1}$ Universidade Federal de Pernambuco
}

September 28, 2020

\begin{abstract}
We report four cases of children who presented skin lesions compatible with viral etiology after close contact with adults with coronavirus disease. Children presented a light exanthematous rash, a mild Pityriasis rosea, erythematous-edematous plaques on the legs with facial rash or papules and umbilicated vesicles on the scrotum without other symptoms.
\end{abstract}

\section{INTRODUCTION}

The coronavirus disease 2019 (COVID-19) is a multisystemic disease with varying degrees of severity caused by the severe acute respiratory syndrome coronavirus 2 (SARS-CoV-2). ${ }^{1}$ Among the affected organs, the SARS-CoV-2 infection can present cutaneous manifestations ${ }^{2}$ with a significant number of reports in adults and hospitalized patients. ${ }^{2,3}$ The cutaneous manifestations can occur before, simultaneously or after the systemic symptoms, therefore they can contribute to the diagnosis of the infection, especially in pre-symptomatic or oligosymptomatic patients. ${ }^{4,5}$

However, only a few cases of dermatological conditions related to SARS-CoV-2 were reported in children. This group has a higher frequency of mild symptoms than adults, ${ }^{6,7}$ not requiring hospitalization in most cases. Therefore, dermatological lesions in outpatient children may be the only symptom of COVID-19. We report four cases of different cutaneous lesions compatible with a viral etiology in children without other symptoms, who had close contact with a sick adult and had been evaluated by dermatologists between may and june of 2020 .

\section{CASE REPORTS}

Case one: Girl, eight-years-old. Father, mother, and grandmother diagnosed with COVID-19. The grandmother was hospitalized for pneumonia associated with COVID-19. One week after the grandmother got sick, the child had a light exanthematous rash on face, behind the ears (Figure 1), on the upper dorsal region, and the sternal region. It was resolved in five days without treatment. She had all vaccinations up to date including rubella. The Serology for SARS-CoV-2 performed one month after the lesions were negative. 


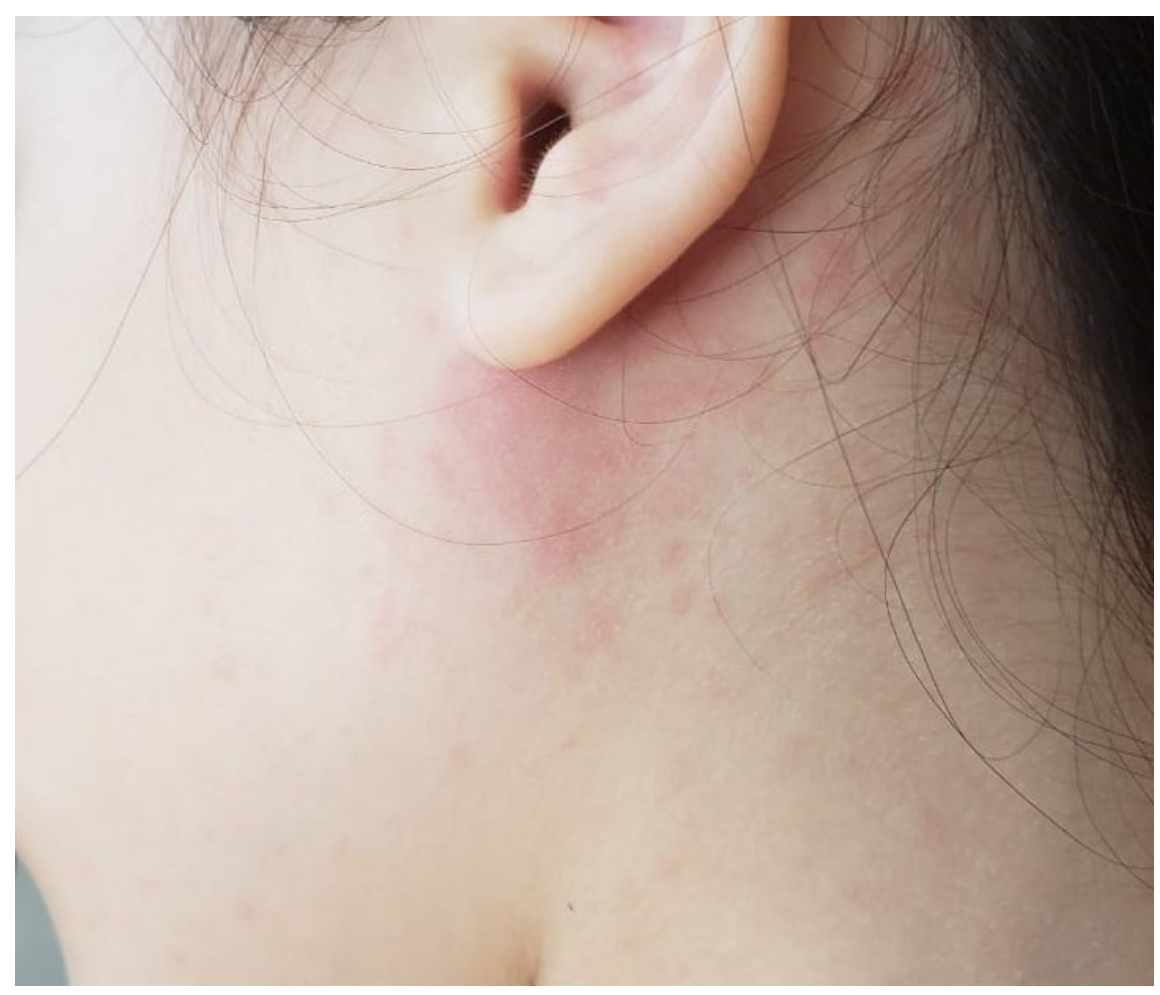

Figure 1: Exanthema clearly visible behind the ear.

Case two: Five-years-old boy presented sparse small plaques with an oval shape and little desquamation on the trunk without pruritus, compatible with Pityriasis rosea (Figure 2). The housekeeper had an abortion fifteen days before, having been diagnosed with COVID-19 during this hospitalization. Her husband is a hospital worker and was diagnosed with coronavirus either. The lesions resolved in fifteen days without treatment and the serology for SARS-CoV-2 performed at this time had negative results. 


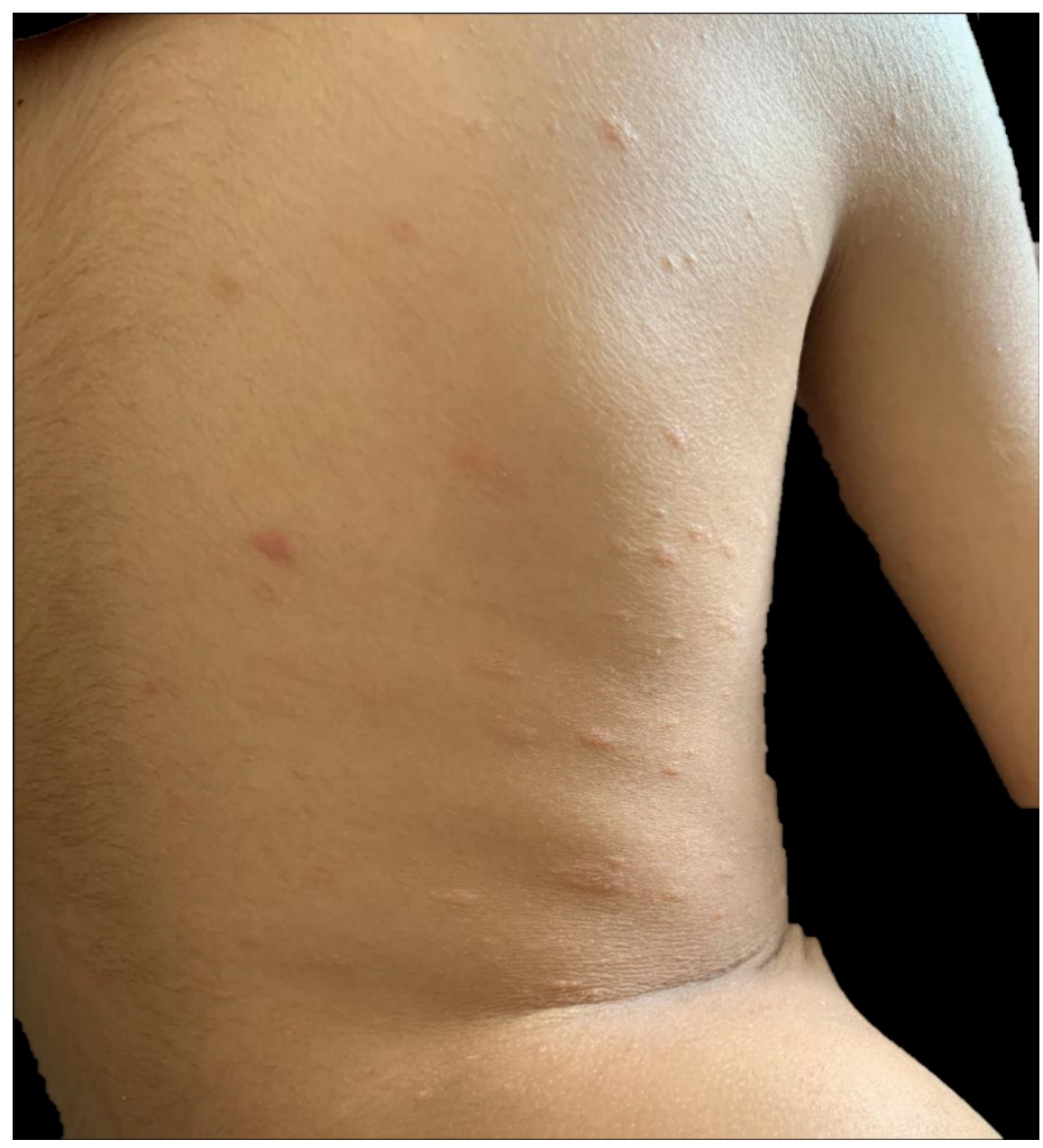

Figure 2: Erythematous oval plaques with light desquamation on the trunk.

Case three and four: Twin male brothers, 1-year-old. The father had a fever, malaise, myalgia and rhinopharyngitis with anosmia. The RT-PCR was positive for SARS-CoV-2. The children were at home for three months and there were no mosquitoes or animals in the place. After three days, the twins presented descending erythematous edematous plaques on the lower limbs, and one of them had a light facial rash. Two days later, the second twin presented a hypersensitivity reaction on the scrotum, with small papules following the midline and umbilicated vesicles (Figure 3). The lesions regressed in three days after the use of hydrocortisone cream $1 \%$ twice a day and did not return after 3 months of follow-up. Children did not show respiratory symptoms and parents refused to perform RT-PCR and the serology tests. 


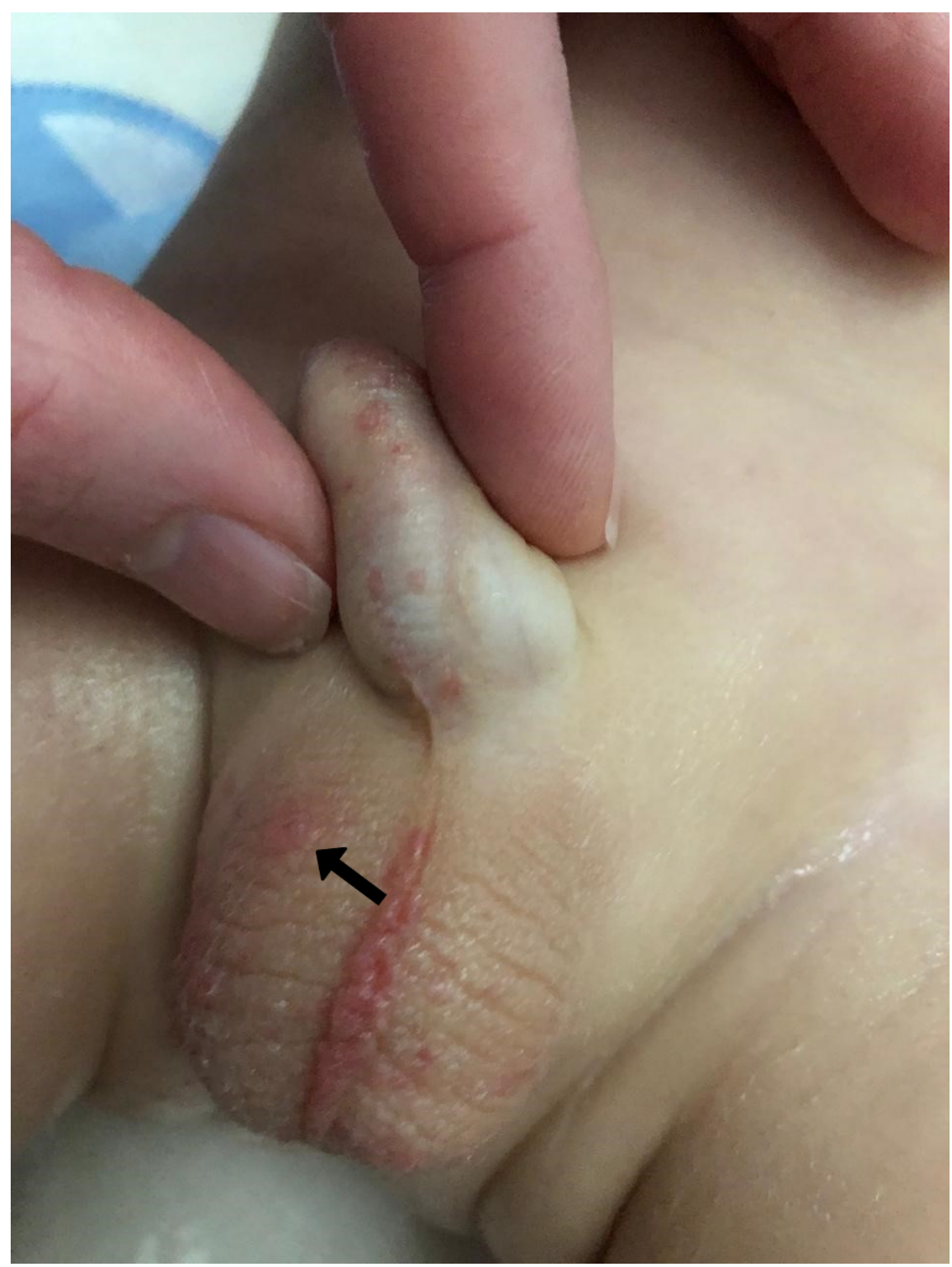

Figure 3: Erythematous plaques and vesicles on the scrotum (arrow).

\section{DISCUSSION}

The dermatological lesions related to Sars-CoV-2 infection most reported in children are maculopapular exanthema, urticarial lesions,${ }^{8}$ erythema multiforme-like lesions, ${ }^{9}$ chilblain-like lesions, ${ }^{4,9}$ and varicella-like lesions ${ }^{10}$ associated or not with pruritus and pain. ${ }^{4}$ They are similar to adults lesions and correspond to moderate to severe skin symptoms. ${ }^{2-4}$ However, the lesions presented by outpatients are not always exactly as previously reported. Mild cutaneous lesions as light exanthematous rash, localized rashes, isolated erythematous-edematous plaques, mild Pityriasis rosea, and petechiae in localized areas were seen in children and adults more frequently after the beginning of the pandemic at the dermatology clinic.

Is difficult to confirm the diagnosis when cutaneous lesions appear without significant systemic symptoms of COVID -19 by many reasons, being the main one the high frequency of false-negative RT-PCR and 
serologies for SARS-CoV-2. ${ }^{9}$ In addition, there is a refusal of the family to submit children to tests $1^{0}$ and the need for a broad viral panel to rule out other hypotheses. ${ }^{5}$ The clue to diagnosis is the close contact with a symptomatic adult and this information should be exhaustively sough.

The mild skin lesions do not require treatment in most cases. When treatment is necessary, short courses of topical corticosteroids associated with antihistamines in case of itching are enough. ${ }^{5}$ These cases corroborate the idea that children have a good prognosis and reinforce that the number of cases of COVID-19 is greater than the official statistics, especially in the pediatric population.

\section{REFERENCES}

1- Cavallo F, Rossi N, Chiarelli F. Novel coronavirus infection and children. Acta biomed 2020; 91(6):172176. https://doi.org/10.23750/abm.v91i2.9586

2- Recalcati S. Cutaneous manifestations in COVID-19: a first perspective. J Eur Acad Dermatol Venereol 2020; 34(5):e212:e213. https://doi.org/10.1111/jdv.16387

3- Hedou M, Carsuzaa F, Chary E, Hainaut E, Cazenave-Roblot F, Masson Regnault M. Comment on "Cutaneous manifestations in COVID-19: a first perspective" by Recalcati S. J Eur Acad Dermatol Venereol 2020; 34(7):e299-e300. https://doi.org/10.1111/jdv.16519

4- Galván Casas C, Català A, Carretero Hernández G, et al. Classification of the cutaneous manifestations of COVID- 19: a rapid prospective nationwide consensus study in Spain with 375 cases. Br J Dermatol 2020; 183(1):71-77. https://doi.org/10.1111/bjd.19163

5- de Medeiros VLS, Silva LFT. Follow-up of skin lesions during the evolution of COVID-19: a case report. [published online ahead of print September 20, 2016]. Arch Dermatol Res. https://doi.org/10.1007/ s00403-020-02091-0

6- Dong Y, Mo X, Hu Y, et al. Epidemiology of COVID-19 Among Children in China. Pediatrics 2020; 145(6):e20200702. https://doi.org/10.1542/peds.2020-0702.

7- Ludvigsson JF. Systematic review of COVID-19 in children shows milder cases and a better prognosis than adults. Acta Paediatr 2020; 109:1088-1095. https://doi.org/10.1111/apa.15270

8- Morey-Olivé M, Espiau M, Mercadal-Hally M, Lera-Carballo E, García-Patos V. Cutaneous manifestations in the current pandemic of coronavirus infection disease (COVID 2019). An Pediatr (Barc) 2020; 92(6):374375. https://dx.doi.org/10.1016\%2Fj . anpede. 2020.04 .002

9- Torrelo A, Andina D, Santonja C, et al. Erythema multiforme-like lesions in children and COVID-19. Pediatr Dermatol 2020; 37:442-446. https://doi.org/10.1111/pde.14246

10- Genovese, G., Colonna, C. and Marzano, A.V. Varicella-like exanthem associated with COVID-19 in an 8-year-old girl: A diagnostic clue?. Pediatr Dermatol 2020; 37:435-436. https://doi.org/10.1111/pde. 14201 